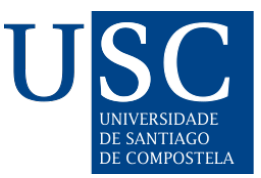

\title{
EI Ministerio Fiscal como especial garante en la prueba de inteligencia: la intensificación de su autonomía
}

\author{
Begoña Gutiérrez \\ España
}

Recibido: 22/09/2020; Aceptado: 12/01/2021

\section{Resumen}

El estudio doctrinal que es objeto de desarrollo en el presente trabajo pretende, sobre la base de instituciones jurídicas preexistentes, proponer ligeras modificaciones legislativas que favorezcan una ponderación más precisa de los intereses puestos en juego durante la sustanciación de un proceso penal, concretamente cuando existe el riesgo de incidencia de materias clasificadas como secretas en el acervo probatorio, motivo por el cual los Fiscales pueden desempeñar un papel fundamental.

Palabras clave: Archivos secretos; Fiscales; Parlamento; derechos humanos; juicio justo.

\begin{abstract}
The survey which is elaborated in this report aims, on the basis of prior legal institutions, to propose little legislative modifications that further a better weigh up of the interests involved during a criminal proceeding, when specially exists the risk of interference by matters classified as secrets in the array of evidences, so that's the reason why the Prosecutors may discharge an essential role.
\end{abstract}

Keywords: Secret archives; Prosecutors; Parliament; human rights; fair trial.

\section{INTRODUCCIÓN}

El presente estudio tiene por objeto analizar al Ministerio Fiscal como Institución garante de la legalidad en la tutela del interés público respecto de materias susceptibles de ser clasificadas como secretas o reservadas por razones de Seguridad Nacional, hallándose incluidas, pues, en el ámbito de aplicación de la Ley 9/1968, de Secretos Oficiales.

En tal sentido, se parte de la premisa de que el Ministerio Público, según la configuración que le otorga nuestro ordenamiento jurídico, forma parte del Poder Judicial en sentido amplio, integrado en él con autonomía funcional de conformidad con lo que, sobre el particular, establece su Estatuto Orgánico.

Asimismo, sin perjuicio de entender que motivos de índole presupuestaria pueden condicionar las posibilidades a corto plazo de disponer de los medios personales y materiales adecuados, no 
resulta descabellado postular una mayor autonomía de la Institución, facilitando de tal modo la interlocución con las Cortes Generales en tanto que representantes de la voluntad general y, por ende, proyección concreta del interés de la sociedad en su conjunto.

No constituye una cuestión baladí, habida cuenta que también están en juego intereses particulares de la persona sometida a un proceso penal que, salvo excepciones rigurosamente justificadas con arreglo al ordenamiento jurídico vigente, ostenta el derecho de acceso a las actuaciones para, en su caso, rebatir o alegar de otro modo lo que a su legítimo interés convenga, respetándose en consecuencia la garantía fundamental a la tutela judicial efectiva.

Así las cosas, previo examen de las instituciones jurídicas ya existentes, acudiendo incluso a figuras de Derecho comparado [tanto en la rama anglosajona como en la continental], se busca fundamentar la propuesta tendente a que la Fiscalía no sea solamente receptora de documentación emanada de las Cortes Generales, sino que éstas también sean destinatarias de planteamientos formulados por el Ministerio Público, ensanchándose la reciprocidad entre órganos de relevancia constitucional.

Evidentemente, al ser una aproximación para procurar que se conjuguen tanto el respeto a la reserva de las materias clasificadas como el respeto a los derechos humanos, no puede hablarse prima facie de una solución cerrada y universal. Resulta obvio que la práctica forense nos sitúa ante planteamientos ciertamente complejos, nunca exentos de opiniones divergentes entre sí.

Por otro lado, se pretende un aumento de la transparencia [sin comprometer la Seguridad Nacional] con el correlativo incremento de la confianza de la ciudadanía en la Administración de Justicia, empresa que se antoja difícil cuando determinados datos no se pueden aportar a una causa criminal, o no se deben exteriorizar.

Y es que, toda vez que el quid de la cuestión estriba en la ponderación adecuada de extremos que revisten suma importancia, el peso de la decisión no debería recaer únicamente en una persona física, sino que habría que "repartir" la hercúlea encomienda entre los organismos propios del Estado democrático de Derecho, cuyas funciones se pueden desarrollar todavía más sin exceder del marco constitucional, especialmente si se atiende a la ubicación sistemática del art. 124 de nuestra Carta Magna, y respetando en todo caso el margen de actuación que permiten los Tratados internacionales suscritos por el Estado español.

\section{LA RELEVANCIA CONSTITUCIONAL DEL MINISTERIO FISCAL}

Tal como afirma García Morillo (2018) "la referencia constitucional a la imparcialidad pone de manifiesto que, aunque el Ministerio Fiscal actúe en un proceso, no es una parte más [...]” (p. 212).

Parte de la doctrina considera que el Ministerio Público no se halla integrado en la Magistratura. En tal sentido, expresa Montero Aroca (2018) que "no forma parte del Poder Judicial organización porque las propias leyes lo excluyen del mismo a todos los efectos. La autonomía del Ministerio fiscal es tanto orgánica como funcional, y así las cosas ¿qué clase de integración puede existir? [...]” (p. 174).

Ahora bien, desde mi punto de vista (y salvo mejor criterio), no se puede obviar la ubicación sistemática del art. 124 CE: en el Título VI, bajo la rúbrica "Del Poder Judicial". Dada la amplitud hermenéutica que permite nuestra Carta Magna, no resulta en modo alguno descabellado sostener que el legislador pueda implementar un mayor grado de autonomía de la Institución, concretada 
en un aumento de la fluidez en el diálogo con otros órganos del Estado y en un desarrollo aún más intenso de las facultades conferidas en aras de la prosecución del interés público tutelado por la ley.

No en vano, nos recuerda Delgado Pugés (2010) que "el Ministère public francés [...] es un órgano con rango de autoridad compuesto principalmente por magistrados [...]” (p.122).

Así pues, partiendo de este somero estudio del Derecho comparado e interpretando con flexibilidad el art. 72.1 CE en relación con el art. 97 del Reglamento del Congreso de los Diputados, se podrían explorar nuevos cauces procedimentales que permitiesen al Ministerio Fiscal una interlocución [en calidad de tertium genus, a medio camino entre juez y parte] con los representantes del pueblo español y, por ende, de la voluntad general (art. $66 \mathrm{CE}$ ), propuestas que se desarrollarán en un ulterior epígrafe.

\section{IGUALDAD DE ARMAS Y CONTRADICCIÓN EN LA PRUEBA DE INTELIGENCIA}

Al decir de Gimeno Sendra (2015) “determinadas 'discriminaciones', que gozan de una justificación objetiva y razonable, no pueden estimarse contrarias al principio procesal de igualdad. Ello es lo que sucede [...] con la especial posición que, en su calidad de 'parte imparcial', pueda ostentar el Ministerio Fiscal dentro del proceso [...], las cuales se manifiestan congruentes con su especial misión de defensa de la legalidad (art. 124.1 CE), y que en el ámbito del proceso, lo han de convertir en el 'guardián de la pureza del procedimiento' [...]” (p. 120).

En este punto, debe hacerse el distingo entre lo que es objeto de análisis en el presente trabajo [concretamente, fuentes de prueba dimanantes de información clasificada como secreta o reservada] frente a los ya estudiados casos de mero secreto sumarial ex art. 302 LECRIM o para los supuestos de intervención de un agente encubierto, circunstancias en las que se le restringe a la Defensa el acceso a las actuaciones en virtud de la LO 19/1994 y del art. 282 bis LECRIM, respectivamente, de conformidad con lo establecido por la Circular FGE nํㅜ일 2018, sobre el derecho de información de los investigados en los procesos penales.

La finalidad primordial de estas líneas estriba en abordar el conflicto que eventualmente se pueda suscitar por la imposibilidad legal de dar traslado a la persona encartada de cierta información incardinada en el ámbito de aplicación tanto de la Ley 9/1968, sobre Secretos Oficiales, como de la Ley 36/2015, de Seguridad Nacional.

Y es que, en lo atinente a esta última disposición normativa, deviene obligado resaltar que en su Preámbulo se indica que "la Seguridad Nacional se entiende como la acción del Estado dirigida a proteger la libertad y el bienestar de sus ciudadanos, a garantizar la defensa de España y sus principios y valores constitucionales [...]". Particularmente, con arreglo al art. 12.1.a), las Cortes Generales son órganos competentes en materia de Seguridad Nacional.

Por otro lado, es menester destacar la sinopsis del art. 109 CE realizada por Pascua Mateo (2003), a cuyo tenor "el control de las Cámaras sobre las materias clasificadas encuentra sólido fundamento constitucional en el artículo objeto de estas líneas y se extiende a tres ámbitos básicos: los secretos oficiales, los gastos reservados y la actividad del Centro Nacional de Inteligencia [...]”.

A su vez, no es baladí que el art. 598 del Código Penal de 1995 tipifique como un delito de descubrimiento y revelación de secretos e informaciones relativas a la Defensa Nacional la conducta en la que incurre "el que, sin propósito de favorecer a una potencia extranjera, se procurare, revelare, falseare o inutilizare información legalmente calificada como reservada o 
secreta, relacionada con la seguridad nacional o la defensa nacional o relativa a los medios técnicos o sistemas empleados por las Fuerzas Armadas o las industrias de interés militar", llevando aparejada la pena de prisión de uno a cuatro años y sin que haya lugar a la aplicación de la eximente ex art. 20.7ํㅡ CP, toda vez que el art. 599.1ํ del mismo Texto punitivo establece que la pena se aplicará en su mitad superior cuando el sujeto activo sea depositario o conocedor del secreto o información por razón de su cargo o destino.

Asimismo, el Derecho comunitario también prevé la posibilidad de que existan excepciones legítimas [por causas plenamente justificadas] al derecho de acceso completo a las actuaciones. Valga como ejemplo la Directiva 2012/13/UE, relativa al derecho a la información en los procesos penales, cuyo Considerando no 32 nos dice que "el acceso a las pruebas materiales, ya sean favorables o desfavorables a la persona sospechosa o acusada, que obren en poder de las autoridades competentes, con arreglo a lo establecido en la presente Directiva, puede ser denegado, de conformidad con la legislación nacional, cuando dicho acceso pueda dar lugar a una amenaza grave para la vida o los derechos fundamentales de otra persona o, cuando la denegación del acceso es estrictamente necesaria para defender un interés público importante. La denegación de dicho acceso debe sopesarse con los derechos de la defensa de la persona sospechosa o acusada, teniendo en cuenta las distintas fases del proceso penal. Las limitaciones a dicho acceso deben interpretarse de forma estricta y conforme al principio del derecho a un juicio equitativo, con arreglo al CEDH y a la interpretación de la jurisprudencia del Tribunal Europeo de Derechos Humanos", idea que se reitera en el art. 7.4 de la antedicha norma europea. En particular, este precepto lo que exige es que la decisión se someta a control judicial [pero no necesariamente que sea un órgano jurisdiccional el que ejecute la decisión]. Nótese que su transposición al Derecho interno español, operada en virtud de la LO 5/2015, no ha implicado la modificación de los arts. 232, 234, 476 y 497 LOPJ [si ello lo contrastamos con la LO 7/2015, comprobaremos que esta última incide en la agenda de señalamientos, pero tampoco ahonda, desde la perspectiva del derecho a la defensa, en el acceso concreto a procesos penales].

Aquí es, precisamente, donde vuelve a entrar en juego el papel de la Fiscalía desde la función contemplada en el art. 3.3 EOMF. Concretamente, el planteamiento que aquí se esboza pivota sobre tres fases básicas:

1a) Suscitación de la duda en cuanto a dar traslado o no a la defensa, ya personada.

$2^{a}$ ) Emisión del informe por el Ministerio Fiscal para evaluación parlamentaria.

$3^{a}$ ) Devolución del expediente al órgano jurisdiccional instructor.

De esta forma, se implementaría un modelo de doble garantía toda vez que, concurriendo eventual prueba de inteligencia, si el aseguramiento de las fuentes conllevara la afectación de los derechos fundamentales garantizados por los arts. 18.2 y 3 CE y 8 CEDH, ya habría tenido lugar el control judicial previo previsto en la LO 2/2002, de 6 de Mayo, razón por la cual el debate sobre el alcance y contenido de aquellos derechos al efectuar la ponderación con otros bienes jurídicos protegidos quedaría, en principio, zanjado.

En otro orden de cosas, no sería recomendable, en mi opinión, que se adoptase en España la figura del "juez testigo", puesto que, además de chocar con el juez de garantías que se prevé implantar si se promulga el nuevo Código procesal penal, se vería mermada la garantía de que no haya un interés directo o indirecto en el resultado del pleito sin ser parte. 
También resulta de sumo interés lo que señala Vervaele (2016) al comentar que "la ocultación de las fuentes de prueba en un proceso penal puede justificarse tanto por razones relativas a inmunidades basadas en el interés público (seguridad nacional, secreto de Estado) como por la finalidad de proteger las fuentes de prueba. [...] Las medidas compensatorias pueden consistir en el acceso a esta información por abogados especiales, no siendo el letrado del acusado y teniendo autorización previa para ello [...]” (pp. 315-317).

Pero en contraposición, en su estudio elaborado a instancias de LIBE [la Comisión de Libertades Civiles, Justicia y Asuntos de Interior del Parlamento Europeo], Bigo, Carrera, Hernanz y Scherrer (2014) pusieron de manifiesto respecto al procedimiento desarrollado en el Reino Unido, entre otros extremos, que "el uso de abogados especiales en audiencias a puerta cerrada no otorga suficiente protección contra el riesgo de un juicio injusto, el Ejecutivo ostenta poderes discrecionales sobre qué materiales son aportados", añadiendo al efecto que "la prueba dimanante de fuentes secretas de inteligencia puede no ser tan robusta como para que se utilice en un proceso público ante un Tribunal" (p. 24). Y por lo que atañe a nuestro país, señalan que "en España la legislación interna no permite formalmente el uso de información clasificada de inteligencia como prueba ante un órgano jurisdiccional" (p. 26).

Ello plantea el reto de discernir entre la prueba legal [aun siendo secreta] y la ilegal, absolutamente nula.

Amén de la cuestión de legalidad ordinaria, ¿pueden estar siendo conculcadas también las previsiones constitucionales?

No es baladí que la Ley de Secretos Oficiales sea discutida y se esté buscando su mejor adecuación al marco democrático. Pero lo primero que debemos preguntarnos es hasta qué punto se puede matizar [mientras no haya una modificación o derogación] sobre la base del párrafo 3o de la Disposición Derogatoria de nuestra Carta Magna y el principio de interpretación conforme.

La solución al dilema no pasa por mirar hacia otro lado, ni tampoco por poner en aprietos al operador jurídico ni al agente de inteligencia. Solventar el problema requiere de una sucesión de aproximaciones que permitan un perfeccionamiento en la delimitación de una institución jurídica, la prueba de inteligencia, que a día de hoy está realmente en fase de desarrollo.

Imaginemos, por un momento, que el concepto de "abogado especial" se atribuyera a un/a letrado/a al margen de la Fiscalía: se pondría en riesgo el derecho de la persona encartada a designar a alguien de su confianza para que le asista jurídicamente. Y recalco la idea de asistir, toda vez que la defensa en un proceso penal no debe ser un ataque a ciegas a la contraparte, sino un debate fundado en Derecho, una dialéctica jurídica. Ahora bien, una vez aclarado este punto, es menester destacar que resulta preferible dar una mínima explicación antes que ocultar eventuales pruebas de cargo y negar su existencia.

Tal vez, la simplificación del modelo nos pueda facilitar la esquematización del objeto de estudio. Aun cuando en el marco de la Unión Europea no hay una uniformidad absoluta entre las legislaciones penales de los Estados Miembros, sí que disponemos de un mínimo común denominador: la Directiva 2012/13/UE. Prima facie, esta norma comunitaria no prohíbe, ni muchísimo menos, la utilización de materias clasificadas. Pero sí exige que la restricción del acceso a determinados datos se verifique conforme al principio de equidad y bajo los parámetros del Convenio Europeo de Derechos Humanos. Y es que este último instrumento jurídico nos puede señalar la clave de bóveda, nada más y nada menos que gracias a una precisión del art. 6.1, al exceptuar la publicidad en determinadas circunstancias. En similares términos se pronuncia el art. 14.1 del Pacto Internacional de Derechos Civiles y Políticos. También sirve de parámetro el art. 
29.2 de la Declaración Universal de Derechos Humanos, que permite limitaciones a los derechos reconocidos en la misma para satisfacer, entre otras, las exigencias del orden público y del bienestar general de la sociedad democrática. Como se puede comprobar, ello entronca con el art. 4.b) de la Ley 11/2002, de 6 de Mayo, reguladora del Centro Nacional de Inteligencia, en consonancia con la Exposición de Motivos del mismo Cuerpo legal.

Estas consideraciones nos conducen a la siguiente fase: la lectura combinada de los arts. $417.2^{\circ} \mathrm{y}$ 707 LECRIM nos aboca a integrar la laguna con las previsiones de los arts. 232, 234, 476.f) y 497.f) LOPJ, pues ya contemplan la posibilidad de que haya determinados extremos en las actuaciones que se exceptúen de la publicidad, por haber sido declarados secretos o reservados conforme a la ley.

La seguridad, entendida como respeto al ordenamiento jurídico para hacer prevalecer el sistema democrático, también pasa por el secreto. El quid de la cuestión estriba en el nivel de ese secreto, así como en evitar que tal secreto favorezca la anarquía y la impunidad.

¿Qué ocurriría si a la defensa se le vetase, por una excesiva declaración de secreto, alguna información que pudiese dar pie a alegaciones de descargo plausibles? ¿Cuáles serían las consecuencias de eventuales sesgos cognitivos? ¿Nos hemos preguntado qué incidencia podría haber en la prueba indiciaria y su valoración por el órgano de enjuiciamiento? ¿Cuál sería la eventual afectación en la operatividad de la segunda instancia? Desde luego, tales planteamientos deberían exteriorizarse ya en fase de instrucción, a fin de no llegar al Plenario con deficiencias en la estricta observancia de las garantías procesales.

Es necesaria la vigilancia del Estado para minimizar el riesgo de que la población incurra en conductas delictivas, pero siempre y cuando todos se sometan a la fuerza de la ley (Pinker, 2002) [el parafraseo se basa en la 3a edición de Paidós, de 2018].

Éstos constituyen, pues, varios de los motivos esenciales para promover que la Fiscalía alcance un nivel de autonomía suficiente como para entablar una relación en condiciones de cuasi-igualdad con el Poder Legislativo, intensificando su protagonismo interlocutor en una suerte de checks and balances en el seno del Poder Judicial, articulándose en base a la interpretación coordinada de los arts. 2, 25, 26 y concordantes del EOMF.

\section{LA INTERVENCIÓN DEL MINISTERIO FISCAL}

\subsection{Un debate por concluir}

Con carácter previo, es menester destacar que el hecho de que el debate sobre la concreción que el encaje del Ministerio Fiscal ha de tener en nuestro sistema constitucional siga aún vigente, nos permite una proposición para articular una función más de la Institución que conlleve la cobertura normativa de una materia como la prueba de inteligencia, más allá del terrorismo y el crimen organizado.

Así las cosas, desprovisto del anclaje a los cometidos propios de la Abogacía del Estado, e integrado con autonomía funcional en el Poder Judicial, el Ministerio Público podría coadyuvar en la ponderación de los intereses legítimos no sólo de las partes procesales, sino también de la sociedad en su conjunto.

En tal sentido, poniendo el foco en el pragmatismo más que en la conceptualización categórica, el carácter de tertium genus flexibiliza el haz de facultades que puede ostentar la Institución. 
Los numerosísimos estudios sobre la naturaleza y alcance de las funciones a desempeñar por la Fiscalía sirven como un valioso soporte; y precisamente, los diferentes puntos de vista sobre el particular constituyen un acicate para seguir avanzando. En este caso, puede afirmarse sin ambages que el esquema clásico que contrapone tesis con antítesis para conseguir la síntesis no nos lleva al bloqueo, sino a un fructífero enriquecimiento que se extrapole a la práctica forense. No en vano, ésta se viene valiendo, desde hace siglos, de la auctoritas para convencer a quien ostenta la potestas de que los argumentos aducidos en el foro son los correctos.

Qué mejor operador jurídico que el Abogado de la sociedad para emitir valoraciones sobre zonas grises entre el secreto de Estado y la transparencia, que al mismo Estado se le exige conforme a los estándares democráticos.

Con acierto indica Granados Pérez (2016) que "todas las atribuciones -hoy en clara tendencia expansiva- no son aspectos desconectados entre sí, sino que tienen un único y común telón de fondo: el Fiscal hoy es -ha de ser- un puente entre los Tribunales y la Sociedad. El representante de la Sociedad ante los Tribunales: un auténtico abogado de la Sociedad que asuma -con la mayor pasión y absoluta imparcialidad- la defensa de los intereses que no son de nadie en particular porque pertenecen a toda la Sociedad [...]" (p. 20).

Por su parte, Zapatero Gómez (2019) nos recuerda que "para el correcto entendimiento de la autonomía funcional resulta sumamente útil el Informe 4 (2009) CCPE, y muy especialmente los puntos 26 y 27 que por su claridad se transcriben:

26.- El ministerio público es una autoridad independiente, que ha de actuar con arreglo a la ley, al más alto nivel. En un Estado democrático, ni el Parlamento, ni ninguna instancia gubernamental, pueden intentar influenciar indebidamente las decisiones del ministerio público relativas a un asunto concreto, para determinar el modo de actuar en un determinado caso, u obligar al ministerio público a modificar su decisión.

27.- La independencia del ministerio público, es imprescindible para permitirle cumplir su misión. Ésta refuerza su papel en el Estado de derecho y en la sociedad, y representa también una garantía para que el sistema judicial funcione con imparcialidad y eficacia y para que todos los efectos beneficiosos que cabe esperar de la independencia de los jueces sean efectivos. A semejanza de la independencia que es propia de los jueces, la independencia que debe reconocerse al ministerio público, no constituye una prerrogativa o un privilegio concedido en interés de sus miembros, sino una garantía para una justicia equitativa, imparcial y eficaz que protege los intereses públicos y privados de las personas afectadas [...]” (p. 159).

Concretamente, en lo que atañe a los asuntos de Estado se pronuncia Guevara Bermúdez (2003) al manifestar que "además del problema que supone que otras personas conozcan el secreto, existe la problemática de si todos los tribunales estarían capacitados para revisar la negativa de la administración de proporcionar la información [...]" (p. 252).

A su vez, cabe destacar lo expresado por la Agencia de los Derechos Fundamentales de la Unión Europea [FRA, por sus siglas en inglés] en su Resumen de 2018 bajo la rúbrica "La vigilancia por parte de los servicios de inteligencia: salvaguardias y tutela de los derechos fundamentales en la Unión Europea- Volumen II". Este Organismo señala que "la falta de conocimientos especializados a la hora de tratar con el secreto y con las cuestiones técnicas también supone un problema para los actores judiciales y extrajudiciales. En el contexto judicial, los Estados miembros han encontrado varias formas de abordar esta cuestión como son el desarrollo de procedimientos contradictorios alternativos que permiten el uso de información clasificada; la creación de mecanismos de cooperación, incluyendo a los servicios de inteligencia, para tratar la falta de conocimientos especializados; y la creación de órganos cuasi judiciales [...]” (p. 8). 
En particular, resultan de sumo interés los dictámenes 7, 15 y 16 consignados en el antedicho Resumen de la FRA (pp. 11-14), que en esencia vienen a sugerir que se establezcan procedimientos específicos, supervisados por un órgano independiente y recabando, en caso de ser necesario, la cooperación de expertos, incluso de los miembros de la comunidad de inteligencia, ampliándose el ámbito operativo de los organismos de vigilancia.

En tal sentido, no es baladí lo que expone la Red Europea de Formación Judicial [EJTN, por sus siglas en inglés] en su Informe Anual de 2018, según el cual el entrenamiento especializado en contraterrorismo "reunió a jueces y fiscales de diferentes Estados miembros de la UE quienes tuvieron la oportunidad de intercambiar sus puntos de vista y experiencia en [...] el uso de la inteligencia como prueba [...]" (p. 37).

Estos parámetros del marco comunitario revisten una ostensible importancia, máxime cuando, tal como ponen de manifiesto Castro Ruano y Borrajo Valiña (2019), "para alcanzar una Unión Europea de Seguridad y Defensa es necesario contar con una mayor cooperación en este ámbito; proceder a una armonización de las culturas estratégicas así como una visión común de las amenazas que nos acechan y las respuestas apropiadas [...]” (p. 198).

A mayor abundamiento, en lo atinente al concepto de Institución, procede traer a colación la cita textual de Maurice Hauriou [en francés, que aquí se traduce al español] efectuada por Soriano García (2017):

"Maurice Hauriou bellamente, expresaba: Una institución es una noción de obra o de proyecto que se realiza y perdura jurídicamente en el seno de un medio social [...]" (p. 678).

Pues bien, en nuestros días también se puede postular sin ambages la reafirmación del Ministerio Fiscal como Institución de relevancia constitucional, integrada con autonomía funcional en el Poder Judicial, base sobre la que pivota el objeto del presente estudio, cual es proponer a la Fiscalía como una interlocutora -plenamente válida y solvente- con el Poder Legislativo a fin de verificar si determinadas fuentes de prueba que se pueden traer a un proceso judicial revisten, efectivamente, los caracteres propios de las denominadas materias clasificadas, tal como concibe el concepto la Ley de Secretos Oficiales y atendiendo a lo dispuesto en la Ley de Seguridad Nacional como criterio hermenéutico.

En puridad, las líneas maestras ya se encuentran suficientemente trazadas, y sólo se requeriría una ligera modificación legislativa [especialmente referida a la LECRIM, al EOMF y a la intendencia de las Cortes Generales] que amplíe las previsiones de la vigente Resolución de la Presidencia del Congreso de los Diputados de 11 de Mayo de 2004, sobre secretos oficiales. Nótese que en virtud de lo establecido por los arts. 49.2.3 y 52.5 de la Resolución de 24 de Febrero de 1982, por la que se ordena la publicación en el Boletín Oficial del Estado del nuevo Reglamento del Congreso de los Diputados, ya se contempla al Ministerio Fiscal como destinatario [por conducto del Presidente de la Cámara] de peticiones, bien sean individuales o colectivas; y además, del traslado llevado a cabo por la Mesa del Congreso de las conclusiones aprobadas por el Pleno de la Cámara en el marco de una Comisión de Investigación, sobre cualquier asunto de interés público.

Así las cosas, y sin perjuicio de que para la consecución de la propuesta aquí analizada se requieran suficientes medios personales y materiales [cuya implicación presupuestaria hace que este particular no sea objeto del presente trabajo], ensanchar las facultades conferidas a la Institución, haciéndola tanto emisora como receptora de cuestiones de interés público en sede parlamentaria, coadyuvaría a concretar el contenido que se define en términos abstractos en nuestra Carta Magna y en el EOMF, máxime cuando el propio art. 541.2 LOPJ se remite expresamente 
al Estatuto, debiéndose entender, pues, la mención de la rúbrica bajo la que se halla ubicado sistemáticamente este último precepto ["instituciones que cooperan con la Administración de Justicia"] en sus términos más amplios, y ello por cuanto la RAE define el verbo "cooperar" como la acción de "obrar juntamente con otro u otros para la consecución de un fin común", concepto ostensiblemente más complejo que el mero "auxiliar".

Podría entenderse, incluso, como la puesta en marcha de un mecanismo intraprocesal de interpretación auténtica, partiendo de la premisa de que la Acusación pública siempre tendrá acceso pleno a las actuaciones, circunstancia que no se puede predicar totalmente en relación con las demás partes personadas [en casos excepcionalísimos, y por causas debidamente justificadas].

Concretamente, el párrafo 1ำ del art. 304 LECRIM dispone que "las Salas de gobierno de las Audiencias territoriales podrán nombrar también un Juez instructor especial cuando las causas versen sobre delitos cuyas extraordinarias circunstancias, o las de lugar y tiempo de su ejecución, o de las personas que en ellos hubiesen intervenido como ofensores u ofendidos motivaren fundadamente el nombramiento de aquél para la más acertada investigación o para la más segura comprobación de los hechos". Bien entendido que no se trataría de Tribunales de excepción, habida cuenta que están proscritos en virtud de lo establecido por el art. 117.6 CE, sino que se trataría de un órgano jurisdiccional incardinado en una mera especialidad procedimental y sujeto, evidentemente, a la obligación de respetar todas y cada una de las garantías que reconoce nuestro ordenamiento jurídico.

Del mismo modo, se podría añadir al meritado precepto de la Ley procesal un apartado con arreglo al cual se facultaría por la Ley rituaria, por ejemplo, a la Fiscalía General del Estado previo dictamen del Consejo Fiscal, para la designación de un Fiscal especial [en atención a su formación específica en materias clasificadas y su ponderación con los derechos humanos, siguiendo los criterios de mérito y capacidad] para intervenir en causas de extraordinarias circunstancias, que serían las que pudieren verse afectadas por el riesgo de colisionar los derechos fundamentales con cuestiones de Estado que, efectivamente, incidan en la Seguridad Nacional.

Es más, en base a los fundamentos arriba expuestos, bien pudiera hablarse del Ministerio Fiscal como un Poder Judicial en sentido lato [no olvidemos su ubicación sistemática en nuestra Carta Magna], que vela por la independencia de los Juzgados y Tribunales [órganos judiciales en sentido estricto, con ocasión del ejercicio de la iurisdictio], procurando la satisfacción del interés social y promoviendo la acción de la justicia en defensa de la legalidad, de los derechos de los ciudadanos y del interés público tutelado por la ley, según dispone el art. $124 \mathrm{CE}$.

Particularmente, respecto a la defensa de los derechos de los ciudadanos, puede constatarse una nítida superposición con lo previsto en el art. 10.1 del Código Deontológico de la Abogacía Española, a cuyo tenor "el deber fundamental de quien ejerce la Abogacía, como actor en la función pública de la Administración de Justicia, es participar en ella asesorando, conciliando y defendiendo en derecho los intereses que le sean confiados. En ningún caso la tutela de tales intereses puede justificar la desviación del fin de justicia al que la profesión se halla vinculada".

No obstante, se presentan matices, toda vez que el Letrado defiende intereses particulares, sin poder apartarse del fin último que es la búsqueda de Justicia como ideal humanista dentro de las posibilidades que otorga el ordenamiento jurídico: esto es, una suerte de concepción primariamente iuspositivista, pero siempre con el fondo subyacente del iusnaturalismo.

A su vez, el Fiscal, sin apartarse de las garantías procesales de cada causa concreta, defiende los intereses de la sociedad en su conjunto. Tal como indicó el Excmo. Sr. D. Carlos Granados Pérez en la ponencia arriba referenciada, el Ministerio Fiscal es el Abogado de la Sociedad. 
No en vano, nos dice el Consejo de Europa, en la página web del Consejo Consultivo de los Fiscales Europeos, que reconoce "el rol esencial del Ministerio Público en el sistema de justicia penal de un Estado gobernado por el Rule of Law".

En cuanto a la Recomendación del Comité de Ministros Rec(2000)19, de entre los principios que promueve destaca especialmente su apartado no 29, en virtud del cual "el Ministerio Fiscal velará por el respeto del principio de igualdad de armas, en especial transmitiendo a las demás partes -salvo excepción prevista por ley- las informaciones en su poder susceptibles de afectar al desarrollo equitativo del proceso". Sobre el particular, ya se ha reseñado arriba que el Ministerio Público ostenta legítimamente una posición privilegiada en el proceso.

A su vez, mutatis mutandis, cabría extrapolar ciertas características propias del estatuto de los Jueces y Magistrados al Ministerio Fiscal, en tanto que manifestación de lo establecido, esencialmente, por los arts. 41, 42 y 47 y concordantes de la Carta de los Derechos Fundamentales de la Unión Europea, el art. 11 DUDH, el art. 14 PIDCP y el art. 6 CEDH.

En tal sentido, el estudio sobre el término anglosajón "accountability", realizado por Hernández Ramos en 2016, pone de manifiesto que el precitado concepto ha evolucionado desde su primigenio contexto contable hasta otro más extenso, equiparable también al de buena administración, señalando al efecto el autor arriba invocado el distingo llevado a cabo por Vegnor Bogdanor entre tipos de responsabilidad según lleven aparejada o no una sanción, así como su equivalencia con la clasificación de Bovens entre los sentidos amplio y estricto de la "accountability"; además, recuerda que la doctrina británica, concretamente Diana Woodhouse y Keith D. Ewing, entienden que lo adecuado es que, en base al criterio de "soft accountability", exista cooperación entre el poder judicial y el Parlamento.

\subsection{Partiendo del secreto instructor}

Las bases de la propuesta, coincidente con el título del artículo objeto de desarrollo, enraízan en las previsiones de la LECRIM sobre el secreto de las actuaciones que afecta tanto a la persona encartada como a su defensa. Nótese que no afecta al Ministerio Fiscal.

Las diferencias estriban en la distinta forma de abordar el acceso a los autos una vez se alza el secreto: cuando concurre con claridad el secreto de Estado, quien se halla bajo investigación tiene vedado el conocimiento de los contenidos afectados. Pero, ¿qué ocurre cuando no está claro hasta qué punto, con arreglo a las leyes de secretos oficiales y de seguridad nacional, los datos específicos de una causa concreta se deben incardinar en los respectivos ámbitos de aplicación de aquellas normas?

Desde la perspectiva de la defensa, no podemos obviar que el desconocimiento de cierta información de la que dispone la Acusación implica un desequilibrio que puede afectar a la igualdad de armas en el proceso. Incluso, el planteamiento de las eventuales alegaciones de descargo puede devenir menos acertada, cuando correlativamente se exige que la asistencia letrada sea efectiva. En condiciones habituales, esto es, cuando no concurren fuentes de prueba dimanantes de la inteligencia, el tenor del discurso defensivo dependerá de la dirección letrada una vez obren en su poder las actuaciones, en su integridad.

Si bien Acusación pública y persona encartada son partes procesales, es a la primera de ellas a la que se le impone ex lege el deber de buscar la veracidad de los hechos objeto de enjuiciamiento, razón por la cual han de establecerse mecanismos de ajuste más "milimétricos" [si se permite la 
expresión] para cuando se da la coyuntura de que el secreto nunca se alza del todo. Al menos, se le tendría que facilitar a la defensa una mínima explicación, aunque fuera somera y sin identificar ni las fuentes ni los métodos de trabajo de los servicios de inteligencia. Esa suerte de "huecos" en el pleito no pueden convertirse en huecos propiamente dichos, sino en tramos vedados, que si son amparados por el secreto de Estado habrán de ser delimitados con la mayor nitidez posible, en aras de la consecución de una transparencia digna de un Estado de Derecho garantista y sociológicamente avanzado.

¿Cuáles son los estándares de transparencia exigibles? Los que determine [o al menos, esboce] la sociedad en cada momento histórico; y el ius, en tanto que creación social, no permanece estático. Nunca será ajeno a la evolución de esa sociedad a la que pertenece. En nuestro caso, resulta evidente que son los estándares europeos los que nos sirven de referencia para tal encomienda, estándares que también son extrapolables al grado de información que pueda recibir la prensa en asuntos que susciten el interés general, aunque no resulta fácil dar cumplimiento a la función prevista por el art. 4.5 del EOMF. Tal vez, estas líneas sirvan para aclarar un poco más el contenido de tal precepto.

\subsection{El necesario papel de la seguridad jurídica}

Si para cualquier ciudadano/a la seguridad jurídica es esencial para conocer las consecuencias de su conducta, a fortiori lo será para los operadores jurídicos, pero más aún [si cabe] para los agentes de inteligencia.

Nótese que, por regla general, se tiende a desconfiar de aquello que está oculto. Si, además, a tal circunstancia se le añade la confusión conceptual entre alegalidad e ilegalidad por la persona lega, se corre el riesgo de mermar la eficacia de los servicios.

Como sabemos, la existencia de una norma escrita previa y taxativa, como manifestación del principio de legalidad, confiere celeridad a los procesos $y$, por ende, eficiencia.

A mayor abundamiento, es menester destacar que la propuesta aquí analizada no debería empecer en absoluto para que mantenga plena vigencia el control previo contemplado en la LO 2/2002, de 6 de Mayo, reguladora del control judicial previo del Centro Nacional de Inteligencia.

Por otro lado, deviene conveniente resaltar que la elección de la Fiscalía no es baladí: habida cuenta que en un Estado de Derecho el sistema adversarial no implica [o no debería implicar en ningún caso] una acérrima enemistad entre quienes sostienen argumentos contrapuestos, no parece recomendable acudir por sistema a la teoría del mosaico. Por ello, el análisis sobre qué datos inocuos en su consideración individual pueden devenir problemáticos si se agrupan debe abordarse con serenidad y cautela.

Asimismo, la denegación de acceso a ciertos extremos de las actuaciones tampoco puede articularse sobre la presunción de culpabilidad del reo, so pena de conculcar los parámetros dados por el Tribunal Europeo de Derechos Humanos. Valgan como ejemplo, entre otras, la STEDH de 20 de Marzo de 2001, Caso Telfner contra Austria, respecto de la necesidad de ausencia de prejuicios en el Tribunal [vid. párrafo 15]; o bien la STEDH de 04 de Marzo de 2010, Caso Mokhov contra Rusia, cuyo párrafo 28 prohíbe manifestaciones de los funcionarios públicos que impliquen la presunción de que la persona encartada es culpable de los hechos que se le imputan, exigiendo el párrafo 29 expresiones cuidadosas sobre el particular.

Así pues, una modificación legislativa que implicara la posibilidad de que, ante zonas grises en la calificación de una materia como clasificada, el Ministerio Fiscal emitiera un informe expresando 
su parecer y diera cuenta a la Comisión parlamentaria competente para que ésta se pronunciara con carácter previo sobre la inclusión o no en las actuaciones [con traslado a todas las partes] de los extremos dudosos que, eventualmente, fuesen susceptibles de hallarse incluidos en el ámbito de aplicación de la Ley 9/1968, contribuiría a minimizar el riesgo de suspicacias que se pudieren generar en el ánimo de la persona encartada o en el de su defensa, quien a su vez ve debidamente cumplida la exigencia dimanante del art. 4 del Código Deontológico de la Abogacía, en relación con el art. 42 del Estatuto General de la Abogacía Española, incluyendo asimismo lo preceptuado por el art. 2.7 del Código de Deontología de los Abogados Europeos.

En consecuencia, por medio de esta fórmula se facilitarían no sólo la fluidez institucional y la confianza de la ciudadanía en la Administración de Justicia, sino también el aseguramiento de que se colman los estándares constitucionales referidos a la tutela judicial efectiva. Nos encontraríamos, de esta manera, ante una clase de "soft accountability", por lo que su observancia no conlleva más que la interlocución leal para con las instituciones y la sociedad en su conjunto, sin dejar de observar [con todo su rigor] las garantías procesales en cada caso concreto.

Y es que en nuestro ordenamiento jurídico las bases para tal proyecto ya están sentadas, máxime cuando disponemos de instrumentos de estudio relativos a la protección de los derechos humanos que coadyuvan a aproximar los valores consignados en los Tratados al terreno de la práctica forense. En tal sentido, no podemos olvidar que no todas las teselas del mosaico son iguales, no todos los mosaicos conforman el mismo dibujo, ni es la misma posición de partida la que ostentan, respectivamente, el cliente-Estado y el cliente-particular.

Finalmente, habida cuenta que tratamos una cuestión de lege ferenda, cabe realizar una última precisión en lo que atañe a la cobertura jurídica de todas aquellas circunstancias difíciles de resolver, en la medida en que se pudieron ver afectadas por alguna laguna legal, que no del ordenamiento en su conjunto: respecto del art. 20.7 CP afirma Mir Puig (2016) que "la solución materialmente adecuada a la realidad y exigencias de la función pública tiene que conducir, pues, a mantener que debe eximir toda orden que no se presente ex ante con una apariencia cualificada de ilegalidad [...]" (p. 512).

\section{CONCLUSIONES}

En atención a todo lo expuesto en los bloques arriba desarrollados, se puede inferir lo que a continuación se reseña:

El Ministerio Fiscal, amén de constituir un órgano clave en el Estado social y democrático de Derecho que proclama nuestra Carta Magna, resulta ser una pieza especialmente relevante en el proceso penal, con un estatus de tertium genus que participa de singulares características, tanto de los órganos que tienen encomendado el ejercicio de la jurisdicción como de una parte procesal más, pero siempre actuando bajo los principios de legalidad e imparcialidad, promoviendo la acción de la Justicia en interés de toda la sociedad.

La meritada Institución, si bien es cierto que está sujeta al principio de jerarquía como trasunto de la unidad de criterio que debe regirla por su especial trascendencia en la Administración de Justicia, desempeñando funciones de una suerte de "cooperación reforzada”, puede alcanzar niveles más elevados de autonomía respecto a los que ahora ostenta, circunstancia que se puede traducir en una mayor facilidad de interlocución fluida y leal con otros órganos de relevancia constitucional. 
Así, se puede afirmar que el Ministerio Público está integrado en el Poder Judicial, entendido este último concepto en sentido amplio, pero no por ello carente de la nota de esencialidad.

El Derecho, como toda creación social, siempre es susceptible de someterse a mejoras tendentes a la prosecución del ideal humanista de Justicia. En tal sentido, con frecuencia los operadores jurídicos se encuentran ante sí con zonas grises difíciles de abordar, como por ejemplo la adecuada ponderación de intereses en juego al colisionar la necesaria transparencia de un proceso judicial con secretos de Estado, cuyo descubrimiento y publicidad podrían acarrear riesgos graves para la Seguridad Nacional y el interés general.

Lo que en la práctica forense sea de "interés general" no presenta facilidad alguna en su descripción, motivo por el cual podría ser una Comisión parlamentaria ad hoc la que, a instancia y previo informe del Ministerio Fiscal como Abogado de la Sociedad, evacuara un escrito reflejando su parecer en casos concretos de manifiesta complejidad.

La igualdad de armas, como integrante del haz de garantías propias de un juicio justo, está en juego en todo proceso. No obstante, la entrada en escena de materias clasificadas puede incidir negativamente en el equilibrio entre partes si no se trata con la suficiente imparcialidad.

Toda vez que el Ministerio Fiscal es un protagonista fundamental del sistema de justicia criminal, circunstancia que viene corroborada, entre otros organismos, por el Consejo de Europa y la UE, sus rasgos definitorios como Institución, tal como elegantemente concebía el término Maurice Hauriou, deben verse reforzados, máxime cuando su intervención se puede ensanchar hacia el concepto anglosajón de "soft accountability", y ello por cuanto sus miembros gozan de solvencia suficiente [y en caso de surgimiento de dudas, pueden ampararse en sus superiores jerárquicos en aras de unificar criterios] para informar detalladamente a la Cámara parlamentaria [en tanto que depositaria y mandataria de la soberanía popular] y, tras el dictamen emitido por la misma, se le pueda dar traslado del mismo a la defensa, de forma tal que no se expliciten los datos sometidos al secreto de Estado, pero plasmando una justificación bastante para entender respetado el principio de contradicción y para considerar razonable la aplicación de la excepción a la regla de publicidad. De esta forma, podríamos equiparar la precitada tramitación a los principios informadores de la figura estudiada, entre otros, por Mark Bovens.

De lege lata, es menester destacar que con arreglo a lo dispuesto en el art. 20.7ำ del Código Penal, ante la eventualidad de que se tramitaran como materias clasificadas aquellas que no fueren merecedoras de tal consideración, por exceder del ámbito de aplicación de la Ley 9/1968, sobre Secretos Oficiales, cabría la eximente completa de obediencia debida. No en vano, a tenor de lo establecido por el art. 103.1 CE, la Administración Pública sirve con objetividad los intereses generales y actúa de acuerdo con los principios de eficacia, jerarquía [...] con sometimiento pleno a la ley y al Derecho, por lo que se debe cumplir toda orden procedente de un superior jerárquico competente para dictarla, siempre y cuando no muestre a limine lo que la doctrina penalista reseña como apariencia cualificada de ilegalidad.

Las cuestiones de lege ferenda que aquí se formulan buscan minimizar las suspicacias que eventualmente pudieren generarse entre los operadores jurídicos ante materias de difícil manejo y, simultáneamente, se pretende incrementar la seguridad jurídica en beneficio de toda la ciudadanía, habida cuenta que las Cortes Generales sí tienen acceso a archivos clasificados como secretos o reservados. 


\section{BIBLIOGRAFÍA}

Agencia de los Derechos Fundamentales de la Unión Europea (2019). La vigilancia por parte de los servicios de inteligencia [versión electrónica]. Viena: Oficina de publicaciones de la Agencia de los Derechos Fundamentales de la Unión Europea. Recuperado de: https://publications.europa.eu/es/publication-detail/-/publication/3cc7eea5-693c-11e8-ab9c-0 1aa75ed71a1/language-es/format-PDF/source-99143402

Bigo, D., Carrera, S., Hernanz, N. y Scherrer, A. (2014). National security and secret evidence in legislation and before the courts: exploring the challenges. Bruselas: Oficina de Publicaciones del Parlamento Europeo. Recuperado de: http://www.europarl.europa.eu/RegData/etudes/STUD/2014/509991/IPOL_STU(2 014)509991_EN.pdf

Castro Ruano, J.L. y Borrajo Valiña, D. (2019). El futuro de la seguridad y la defensa en la UE post-Brexit: el salto a la integración. Cuadernos Europeos de Deusto, 60, 187-217. DOI: http://dx.doi.org/10.18543/c ed-60-2019pp187-217

Council of Europe. Consultative Council of European Prosecutors. Recuperado de: https://www.coe.int/en /web/ccpe [consulta en fecha 18/09/2020]

Delgado Pugés, I. (2010). La composición del Ministerio Fiscal en España y en Francia: cuestiones de traducción y terminología. Anales de Filología Francesa, 18, 119-135. https://dialnet.unirioja.es/desc arga/articulo/3709843.pdf

European Judicial Training Network (2019). Annual Report 2018 [versión electrónica]. Recuperado de: http://www.ejtn.eu/Documents/About\%20EJTN/EJTN\%20Documentation/EJTN-Annual-Report 2018_Web.pdf

Gimeno Sendra, V. (2015). Derecho Procesal Penal. Navarra: Civitas.

Granados Pérez, C. (2016). Independencia, imparcialidad y dependencia jerárquica [versión electrónica]. Madrid: Centro de Estudios Jurídicos. Recuperado de: http://www.cej-mjusticia.es/cej_dode/flash/eb ook/assets/img/cejponencia1480602440736/cejponencia1480602440736.pdf

Guevara Bermúdez, J.A. (2003). Los secretos de Estado (un acercamiento a sus controles en el Estado de Derecho). (Tesis doctoral). Universidad Carlos III. Madrid. Recuperado de: https://e-archivo.uc3m.es/ handle/10016/12283

Hernández Ramos, M. (2016). El cambio de paradigma en el control del Poder Judicial como Institución en España. De la responsabilidad judicial a la judicial accountability. En J. Solanes Mullor (coord.), Independencia Judicial y Estado Constitucional. El estatuto de los jueces (pp. 134-167). Valencia: Tirant lo Blanch.

López Guerra, L., Espín, E., García Morillo, J., Pérez Tremps, P. y Satrústegui, M. (2018). Derecho Constitucional, volumen II. Los poderes del Estado. La organización territorial del Estado. Valencia: Tirant lo Blanch.

Mir Puig, S. (2016). Derecho Penal, Parte General (10ae ed.). Barcelona: Reppertor.

Montero Aroca, J., Gómez Colomer, J.L. y Barona Vilar, S. (2018). Derecho Jurisdiccional I, Parte General. Valencia: Tirant lo Blanch.

Pascua Mateo, F. (2003). Sinopsis artículo 109- Constitución Española. Recuperado de: http://ww w.congreso.es/consti/constitucion/indice/sinopsis/sinopsis.jsp?art=109\&tipo=2 [consulta en fecha 18/09/2020]

Pinker, S. (2018). La Tabla Rasa (3ª ed.). Barcelona: Paidós.

Soriano García, J.E. (2017). De nuevo, el Poder, la Administración y los Jueces. En L. Parejo Alfonso y J. Vida Fernández (coords.), Los retos del Estado y la Administración en el siglo XXI: Libro Homenaje al Profesor Tomás de la Quadra-Salcedo Fernández del Castillo, tomo I (pp. 659-694). Valencia: Tirant lo Blanch. 
Vervaele, J. (2016). Prueba de inteligencia. En A. Díaz Fernández (dir.), Conceptos Fundamentales de inteligencia (pp. 313-319). Valencia: Tirant lo Blanch.

Zapatero Gómez, J. (2019). El buen Fiscal. Valencia: Tirant lo Blanch. 